\title{
Protein F, a fibronectin-binding protein of Streptococcus pyogenes, also binds human fibrinogen: isolation of the protein and mapping of the binding region
}

\author{
Viacheslav Katerov, ${ }^{1,2}$ Andrej Andreev, ${ }^{1}$ Claes Schalén ${ }^{2}$ \\ and Artem A. Totolian'
}

Author for correspondence: Claes Schalén. Tel: +4646173284 . Fax: +4646189117.

\footnotetext{
1 Institute of Experimental Medicine, Academy of the Medical Sciences, St Petersburg, Russia

2 Department of Medical Microbiology, University of Lund, Solvegatan 23. S-22362 Lund, Sweden
}

During screening of a gene library of Streptococcus pyogenes type M15 for fibrinogen-binding material, a protein of approximately $100 \mathrm{kDa}$, encoded outside the vir region, was found. DNA sequencing revealed this component to be identical to protein $F$, a fibronectin-binding protein. Isolation of the recombinant protein, termed F15, was performed by the use of fibrinogen affinity chromatography. The affinity constant $\left(K_{\mathrm{a}}\right)$ of protein F15 for fibrinogen, $1.25 \times 10^{7} \mathrm{~mol}^{-1}$, was lower than that for fibronectin, $1.8 \times 10^{8} \mathrm{~mol}^{-1}$. The fibrinogen-binding domain was located in the $\mathbf{N}$-terminal part of the molecule, while the fibronectin-binding domains, as previously determined, were in the C-terminal portion of protein $F$. To examine the amino acid sequence heterogeneity of protein $F$, the 5 ' part of the prtF gene, corresponding to the $\mathbf{N}$-terminal variable region of the protein, was amplified by PCR from 12 strains of S. pyogenes belonging to six different M-types. Alignment of these nucleotide sequences indicated that the $5^{\prime}$ portion of the prtF gene had probably undergone a number of intragenic recombination and horizontal gene transfer events, allowing a pattern of structural diversity of protein $F$ observed earlier for some other streptococcal virulence factors. There was no strict correlation between $M$-type and nucleotide sequence of the variable region of the prtF gene and, compared to streptococcal M protein, the overall variation observed for protein $F$ appeared more limited.

Keywords: Streptococcus pyogenes, fibrinogen, fibronectin, protein F

\section{INTRODUCTION}

Streptococcus pyogenes (group A streptococcus), a globally prominent cause of human disease, may give rise to a variety of acute infections, such as pharyngotonsillitis, impetigo, erysipelas, septicaemia and a generalized toxic syndrome. The non-suppurative sequelae, namely rheumatic fever and acute glomerulonephritis, characteristically associated with $S$. pyogenes are still highly prevalent in the developing world. The adaptation of $S$. pyogenes as an almost exclusively human pathogen may at least in part reside in its

Abbreviation: OF, serum opacity factor.

The GenBank accession numbers for the nucleotide sequences reported in this paper are AF009908-AF009920. unusual ability to interact with human plasma and matrix tissue components. Thus, $M$ protein, a typespecific virulence factor conferring resistance to phagocytosis, has been known for some time to bind fibrinogen; whether such resistance is somehow related to the binding of fibrinogen has been debated (Whitnack et al., 1988; Fischetti, 1989). An interaction between M protein and another plasma protein, complement inhibitory factor $\mathrm{H}$, was also proposed to account for its antiphagocytic effect, although recently this was not corroborated when isogenic mutants were studied (Horstmann et al., 1992; Perez-Casal et al., 1995). Many strains of $S$. pyogenes bind the Fc parts of IgG or IgA, or both, as well as other plasma proteins through $\mathrm{M}$ - or M-like proteins, which show extensive immunochemical variation within the species (Fischetti, 1989). S. pyogenes may also bind and activate plasminogen (Berge \& 
Sjöbring, 1993; Ben Nasr et al., 1994) or directly bind plasmin (Lottenberg et al., 1994), which might facilitate tissue spread of the organisms.

During the last decade, several interactions between $S$. pyogenes and extracellular matrix components have been reported and also proposed to be of relevance for tissue adhesion and invasion. Many strains were, for example, found to be capable of binding fibronectin (Kuusela et al., 1985), vitronectin (Chhatwal et al., 1987), collagen (Speziale et al., 1987; Kostrzynska et al., 1989) or laminin (Switalski et al., 1984). A surface protein with affinity for fibronectin, designated $\mathrm{Sfb}$ or protein F, has now been characterized in detail (Sela et al., 1993; Talay et al., 1993, 1994). This protein was also shown to be of importance for the attachment of the organisms to some host epithelial cells (Hanski \& Caparon, 1992; Hanski et al., 1992; Okada et al., 1994). Another protein, exhibiting similar fibronectin-binding regions as protein $\mathrm{Sfb}$, was recently discovered (Kreikemeyer et al., 1995). In addition, an unrelated surface protein of $S$. pyogenes which exhibited dual binding of fibrinogen and fibronectin was reported (Courtney et al., 1994). Finally, binding of fibronectin to streptococcal serum opacity factor (OF), a type-variable lipoproteinase of undefined biological role, was found (Rakonjac et al., 1995). Obviously, the capacity of more than one streptococcal factor to bind a certain host molecule, such as fibronectin, suggests that this interaction may be of relevance for microbial survival.

In the present work, it was revealed that streptococcal protein $\mathrm{F}$ binds fibrinogen in addition to fibronectin. It was, therefore, of interest to purify the protein in order to study its binding characteristics, in particular to find out whether the binding of fibrinogen and fibronectin, two host molecules sharing few structural or biological properties, took place through separate or common molecular sites. Furthermore, the amino acid sequence variability of protein $\mathrm{F}$ from some different $\mathrm{M}$-types of S. pyogenes was studied.

\section{METHODS}

Bacterial strains. Streptococcus pyogenes strain EF1949, type M15, was the source of chromosomal DNA for gene cloning. Escherichia coli JM109 was the host for vector and recombinant plasmids, and E. coli NM539 for the propagation of recombinant phages. E. coli $\mathrm{HB} 101$ was used for highefficiency transformation after preparation of recombinant plasmids using the Erase-a-Base System (Promega). E. coli BL21(DE3) (Novagen) was the host strain used for expression of a fibrinogen-binding protein.

The following reference strains of $S$. pyogenes, obtained earlier from the respective laboratories, were tested for nucleotide sequence alignment of part of the prtF gene (Hanski \& Caparon, 1992): M4 (281C; Colindale, UK), M4/243 (Umeå, Sweden), M4/118 (Prague, Czech Republic), M12/103 (Prague), M12 (195/2110; Prague), M12 (100085; Colindale), M15/106 (Prague), M18/104 (Prague), M18 (SS-36; CDC, Atlanta, GA, USA), T27 (SF40; Colindale), M48 (B4C3/48/1; St Petersburg), M49 (245/2110; Prague).

Host proteins. Purified human monoclonal IgG1, IgG2, IgG3, $\operatorname{IgG} 4, \operatorname{IgA}, \operatorname{IgD}$ and $\operatorname{IgM}$ were gifts from Professor A. Grubb,
Department of Clinical Chemistry, University of Lund, Sweden. Laminin (human placenta), collagen type I (calf skin) and vitronectin (rat plasma) were from Sigma. Purified complement component $\mathrm{C1q}$ was obtained from $\mathrm{Dr} \mathrm{A}$. Sjöholm, Dept of Medical Microbiology, University of Lund. Human serum albumin was from KABI-Pharmacia.

DNA preparations. Streptococcal chromosomal DNA was prepared as described by Haanes et al. (1992). Lambda bacteriophage and plasmid DNA were isolated by standard procedures (Maniatis et al., 1982). Plasmid DNA was also prepared by use of the Qiagen Plasmid Kit, according to the instructions of the manufacturer.

DNA probes. Recombinant plasmid pDH76, containing the DNA fragment encoding the so-called A repeats of the streptococcal $f c r A 76$ gene (Heath \& Cleary, 1989), was kindly provided by Professor P. P. Cleary, Department of Microbiology, University of Minnesota, Minneapolis, USA. The recombinant insert of plasmid pDH56, containing the major part of the $f(r A 76$ gene, was labelled with digoxigenin and used as a probe for the $f c r A$ gene.

Molecular cloning. A gene library of strain EF1949 DNA in phage $\lambda$ GEM11 (Promega) was obtained by established methods (Maniatis et al., 1982). The Packagene in vitro packaging system (Promega) was used for packaging of ligated DNA into phage particles and plasmid pGEM7Zf $(+$ ) (Promega) for subcloning in E. coli JM109. Expression plasmid vector $\mathrm{pET}-21 \mathrm{a}(+)$ [or pET22b(+) for the pEFGR153 clone] (Novagen) was used for the forced cloning of PCR fragments containing various fragments of a fibrinogen-binding protein gene. Preparation of competent cells of E. coli strains JM109, BL21(DE3) or HB101, and transformation, were according to the Promega Protocols and Applications Guide. Phage manipulation, DNA restriction, ligation and agarose gel electrophoresis were carried out according to well-known protocols (Maniatis et al., 1982). DNA hybridization analysis with digoxigenin-labelled A repeats of $f c r A 76$ DNA probes was according to the instructions given in DIG DNA Labelling and Detection Kit (Boehringer-Mannheim).

DNA sequencing. DNA was sequenced by the dideoxy chaintermination method (Sanger et al., 1977). Overlapping doublestranded templates for sequencing were prepared with the Erase-a-Base System (Promega). Sequencing reactions were done with the Sequenase version 2.0 Kit (USB) from the SP6 or T7 promoter primers.

PCR and primers. The PCR reaction was run in a $50 \mu \mathrm{l}$ format with a MiniCycler (MJ Research) according to standard procedures (Saiki et al., 1988). Primers used are listed in Table 1. The primers forward/reverse 1 were selected to amplify a DNA fragment encoding the whole fibrinogen/fibronectinbinding protein, whereas in the case of primers forward/ reverse 2 the C-terminal, fibronectin-binding domains (Sela et al., 1993) were not included. The primers UFBDF/UFBDR were designed to amplify the upstream fibronectin-binding domain, primers FBREPF/FBREPR to amplify the fibronectinbinding (type 2) repeats, and primers FgREPF/FgREPR for the type 1 repeats.

Purification of fibrinogen. Since it was found to be contaminated with fibronectin, commercial human fibrinogen (KABI-Pharmacia) was purified by absorption of fibronectin to gelatin-Sepharose as reported by Yamada (1982) with minor modifications. The concentration of fibrinogen was measured using the $\mathrm{D}_{\mathrm{C}}$ Protein Assay (Bio-Rad) and its purity was confirmed by SDS-PAGE and Western blot analysis. Fibronectin, as well as the immunoglobulin fractions of rabbit antisera specific for fibrinogen or fibronectin (Dakopatts), 
Table 1. PCR primers used to amplify DNA fragments encoding regions of the fibrinogen/fibronectin-binding protein of $S$. pyogenes

\begin{tabular}{|llc|}
\hline $\begin{array}{l}\text { Oligonucleotide } \\
\text { function }\end{array}$ & \multicolumn{1}{c}{ Sequence $\left(\mathbf{5}^{\prime}\right.$ to $\left.\mathbf{3}^{\prime}\right)$} & $\begin{array}{c}\text { Nucleotide } \\
\text { position }\end{array}$ \\
\hline Forward & GAT TTG GAT CCA CTT TAG TGG GAG TCT TT & $535-563$ \\
Reverse 1 & GCA TAT GAG CTC ATT ATT TCT TAT GGA AC & $2517-2545$ \\
Reverse 2 & ATT GTT GAG CTC ATA ACG AGG AAC TTC A & $1691-1718$ \\
UFBDF & GTT AGA TGG ATC CGA AGT CCC TGA AAA A & $1643-1670$ \\
UFBDR & CTG TCG AGC TCA TAT TTC CTG AAA AAC C & $1830-1857$ \\
FBREPF & GGT TTT TCA GGA TCC ATG GTT GAG ACA G & $1830-1857$ \\
FBREPR & CAA CAG AGC TCA CTG TTT CAC TGA AAC C & $2274-2301$ \\
FgREPF & CGA GTT GGA TCC CAC TCC AAT TCC CG & $1270-1296$ \\
FgREPR & GGT AAG TGA GCT CTA GGT TTT TCA GGG & $1661-1688$ \\
\hline
\end{tabular}

* GenBank accession number: AF009908.

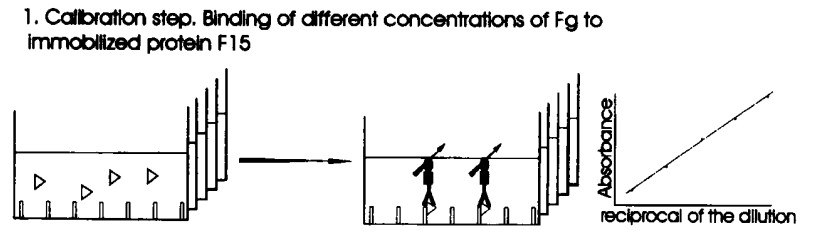

2. Binding reaction of $\mathrm{Fg}$ and protein $\mathrm{F} 15$ in solution

(concentration of $\mathrm{Fg}$ is constant, concentration of proteln $\mathrm{F} 15$ varies) and subsequent measurement of unreacted Fg

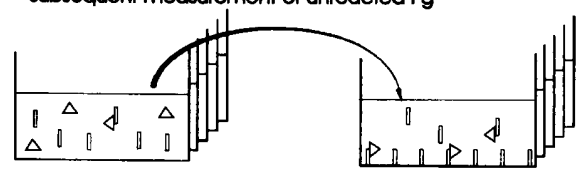

3. Calculation of the dissociation constant according to equation:

$\left.A /\left(A_{0}-A\right)=1+K /\left(a_{0}-1 / A_{0}-A\right)\right) / A_{0}$

Where: $A_{b}$ - the absorbance measured for $\mathrm{Fg}$ in the absence of protein $\mathrm{F} 15$

A - the cosoribance measured in EIISA

$i_{0}$ - total concentration of $\mathrm{Fg}$ in solution

$a_{0}$ - total concentration of protein $\mathrm{F} 15$ in solution

$\triangleright$ fibrinogen

$\lambda$ ontl-fg ontibodies

- conjugant of protein A with Peroxidase

1 protein $\mathrm{F}$

Fig. 1. Schematic outline of experiment for determination of the dissociation constant between fibrinogen and protein F15 by ELISA, as modified from Friguet et al. (1985). The analogous experiment was performed for fibronectin and protein F15.

were kindly provided by Dr B. Cederholm, Department of Medical Microbiology, University of Lund. The respective antiserum was adsorbed on immobilized fibrinogen or fibronectin to remove any cross-reactive antibodies. For demonstration of fibrinogen-binding proteins, fibrinogen was labelled with digoxigenin-3-O-methylcarbonyl- $\varepsilon$-aminocapronic acid- $N$-hydroxysuccinimide ester and digoxigenin-3-Osuccinyl-[2-(N-maleimido) ]ethylamide and then detected ac-

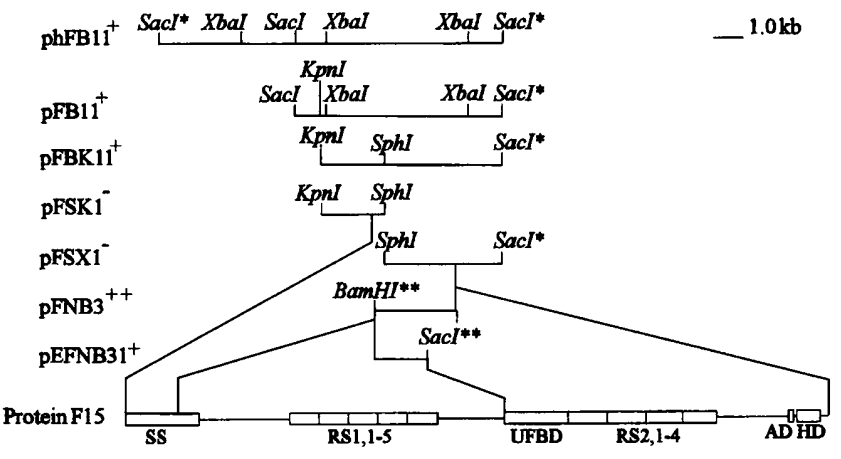

Fig. 2. DNA restriction maps of the recombinant phage (phFB11) and plasmid ( $p$ ) clones and structure of the fibronectin/fibrinogen-binding protein F15. A superscript plus indicates clones expressing fibrinogen binding; a superscript minus indicates clones without expression of fibrinogen binding; SaCl*, restriction site from the $\lambda \mathrm{GEM} 11$ cloning vector; SaCl** and BamHI**, restriction sites introduced with PCR primers. Protein F15 domains (Sela et al., 1993): SS, signal polypeptide; RS1,1-5, five type 1 repeat units with unknown function; UFBD, upstream fibronectin-binding domain; RS2,1-4, four type 2 repeat units with fibronectin-binding activity; $A D$, membrane-anchoring domain; HD, hydrophobic domain.

cording to the description of the manufacturer (Boehringer Mannheim).

Isolation of recombinant fibrinogen-binding protein. A fibrinogen-binding protein (protein F15) was purified from a sonicate extract of induced E. coli BL21(DE3) cells harbouring recombinant expression plasmid pFNB3. Following fractionation with ammonium sulphate, the fraction which precipitated at $30 \%$ saturation was applied to a column packed with Sephacryl S-200 HR (KABI-Pharmacia) and equilibrated with $15 \mathrm{mM}$ phosphate-buffered saline (PBS) containing $10 \mathrm{mM}$ benzamidine hydrochloride, $\mathrm{pH} 7 \cdot 2$. Fractions were collected and screened for fibrinogen-binding activity using digoxigenin-labelled fibrinogen as described below. Fractions exhibiting fibrinogen-binding activity were pooled and applied to a fibrinogen-Sepharose column in the same buffer. After 
(a)

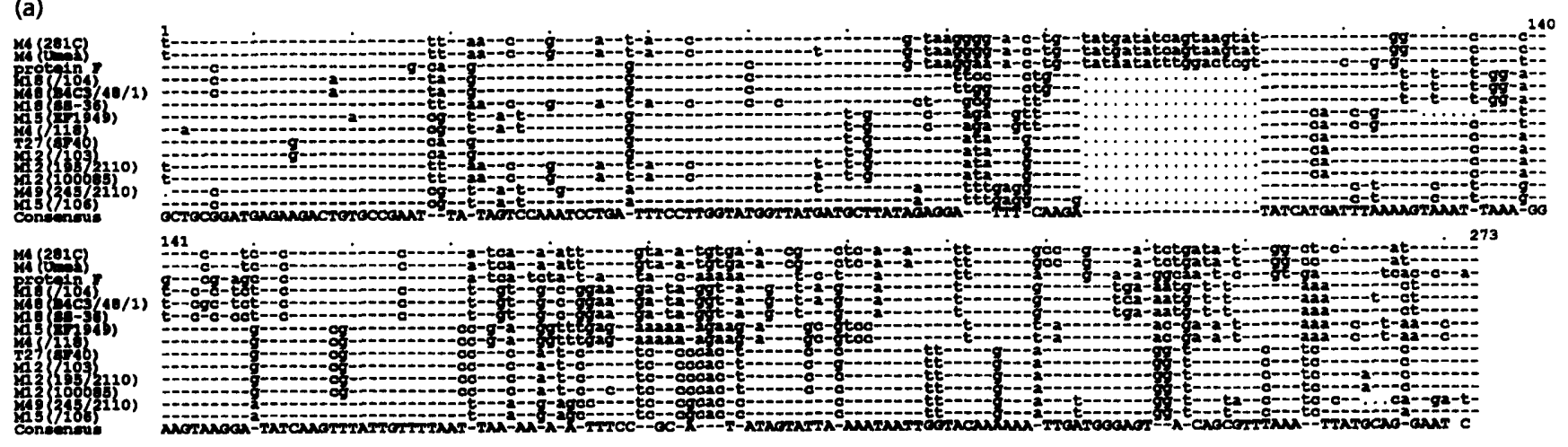

(b)

$m(281 c)$

W (Uned)

protein $:$

ins $(1 / 104)$

M8 (BAC3/48/1)

$28(s 8-36)$

25 (2)1949)

m(1/18)

$227(8740)$

$102(1 / 203)$

$102(195 / 2110)$

$102(100085)$

Mag (245/2110)

cos (1/106)

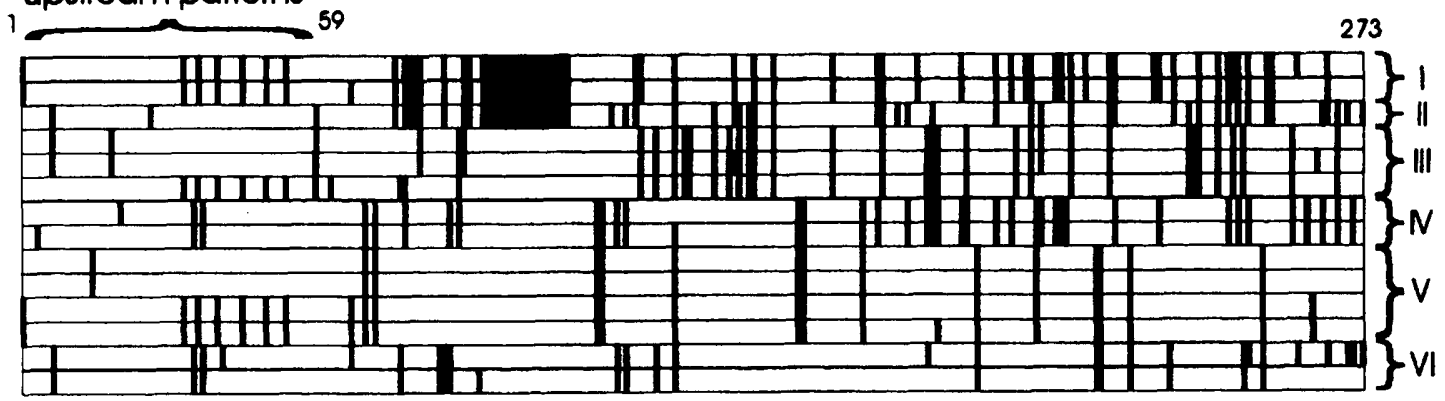

Fig. 3. (a) Alignment of the sequences of the initial 273 nucleotides of the prt $F$ gene, starting at a position corresponding to the first amino acid codon of the mature protein $F$ of $S$. pyogenes. The strains included are listed in Methods. The sequences identified have been deposited in GenBank (accession numbers: AF009913, AF009914, AF009918, AF009919, AF009920, AF009908, AF009910, AF009912, AF009909, AF009915, AF009911, AF009916, AF009917). (b) Schematic representation of the sequence variation pattern shown in (a). The vertical lines denote the sites of nucleotide polymorphism. Six distinct patterns are indicated by Roman numbers (I-VI). Nucleotide positions not included in the consensus sequence are not shown.

washing, protein bound to the affinity matrix was eluted with $0 \cdot 1 \mathrm{M}$ glycine/ $\mathrm{HCl}$ buffer, pH $2 \cdot 8$, containing $10 \mathrm{mM}$ benzamidine hydrochloride. Following dialysis, the purity of the isolated protein was confirmed by SDS-PAGE and Western blotting using loadings of $5 \mu \mathrm{g}$ of the purified fibrinogenbinding protein.

Rabbit antiserum to protein F15. The $30 \%$ ammonium sulphate precipitated fraction of the sonicate extract of the induced culture of E. coli BL21(DE3)(pFNB3) was used for immunization of rabbits in order to obtain antibodies to protein F15. At monthly intervals, $0.5 \mathrm{ml}$ sonicate together with complete (initial injection) or incomplete (subsequent four injections) Freund's adjuvant was injected subcutaneously. The antiserum was extensively adsorbed with a mixture of sonicates of induced and non-induced $E$. coli BL21(DE3) harbouring vector plasmid pET21a $(+)$.

Western blotting. SDS-PAGE was done according to Laemmli (1970). Electrotransfer of proteins from polyacrylamide gels was done by standard methods (Andersen, 1984). After electroblotting, the nitrocellulose membrane was blocked with $3 \%$ skim milk (Oxoid) in PBS for $1 \mathrm{~h}$. Fibrinogen- and fibronectin-binding proteins were detected by incubation with fibrinogen or fibronectin $\left(2.0 \mathrm{~g} \mathrm{l}^{-1}\right)$ followed by the respective antibody (dilution 1:250), peroxidase-labelled protein $\mathrm{A}$ (Sigma) and $p$-phenylenediamine for development. Alternatively, fibrinogen-binding proteins were detected by incubation for $1 \mathrm{~h}$ at $20^{\circ} \mathrm{C}$ with digoxigenin-labelled fibrinogen $\left(2.0 \mathrm{~g} \mathrm{l}^{-1}\right)$ with subsequent development by alkaline-phos- phatase-labelled anti-digoxigenin antibody as detailed by the manufacturer (Boehringer).

Affinity constant determinations. The association constants $\left(K_{\mathrm{a}}\right)$ of protein F15 for fibrinogen and fibronectin in the liquid phase were determined as described by Friguet et al. (1985) with minor modifications. In brief, a constant amount of either fibrinogen or fibronectin was incubated at room temperature for $1 \mathrm{~h}$ with various quantities of protein F15. The amount of unbound fibrinogen or fibronectin was subsequently measured by indirect ELISA using protein F15 for coating of microtitre plates. The general scheme of the experiment is shown in Fig. 1.

\section{RESULTS}

Isolation and sequencing of the gene of a fibrinogenbinding protein

A phage $\lambda$ library of $S$. pyogenes EF1949 (type M15), was screened for expression of proteins able to bind fibrinogen. Several positive recombinant clones were identified and tested for hybridization with the fcrA76 Arepeat probe to detect the $f(r A 15$ gene encoding the FcRA15 fibrinogen-binding protein (Katerov et al., 1994). Five positive phage clones which did not hybridize with the $\mathrm{f} c r A 76$ A-repeat probe, yet reacted with digoxigenin-labelled fibrinogen, were further analysed. 
DNA from these phage clones was isolated and a restriction map was created for each of them. A $6 \mathrm{~kb}$ $\mathrm{XbaI}$ fragment was common to all five. A slightly larger SacI fragment of $8 \mathrm{~kb}$ from phage phFB11 (Fig. 2) was subcloned into the plasmid vector $\operatorname{pGEM} 7 Z(+)$. The recombinant plasmid, designated pFB11, when transformed into $E$. coli JM109, expressed a fibrinogenbinding protein. The insert was shortened to approximately $7 \mathrm{~kb}$ by subcloning a $S a c \mathrm{I}-K p n \mathrm{I}$ fragment and the resulting plasmid, $p F B K 11$, still expressed a fibrinogenbinding protein. To generate contiguous deletion variants of the recombinant insert for sequencing, the $7 \mathrm{~kb}$ SacI-KpnI fragment was further subcloned into two plasmids, pFSX1 and pFSK1 (Fig. 2).

The 2801 nucleotide pairs of inserts of plasmids pFSX1 and pFSK1 were sequenced from a common $S p h \mathrm{I}$ restriction site (Fig. 2) (GenBank accession number AF009908). One long ORF, starting from position 450 and finishing at position 2504, was found. This ORF $(p r t F)$ encoded a protein of 685 amino acid residues with extensive amino acid sequence relatedness $(87 \%$ similarity, $79 \%$ identity) to the previously described fibronectin-binding protein, protein F (Sela et al., 1993). As expected, the deduced protein F15 exhibited all typical features earlier described for SfbI or protein F of other serotypes (Sela et al., 1993; Talay et al., 1993, 1994). It contained a signal polypeptide 56 amino acids in length, a variable region, five type 1 repeats of unknown function, a spacer region, an upstream fibronectinbinding domain (UFBD), four fibronectin-binding repeats and a C-terminal region typical for streptococcal surface proteins (Fig. 2).

Since the principal cell-surface-associated virulence factor of $S$. pyogenes, the $M$ protein, exhibits extensive Nterminal sequence variation, thereby complicating vaccine development, we studied whether this would apply to protein $\mathrm{F}$ as well, knowing that gene variability occurred mainly in the $\mathrm{N}$-terminal part (Talay et al., 1994). To analyse the extent of sequence diversity within the variable region (Talay et al., 1994), approximately 300 nucleotides from the signal sequence cleavage site were determined for an additional $12 \mathrm{~S}$. pyogenes strains of different $\mathrm{M}$-serotypes. The alignment of this part of the gene for protein F of the present M15 strain, the 12 other strains and the previously described protein $\mathrm{F}$ gene sequence is shown in Fig. 3(a). Aligning all strains, six types of nucleotide pattern were distinguished between nucleotide positions 60 and 270 (Fig. $3 \mathrm{~b}$ ). Several nucleotide sequence variation patterns can be easily identified even by visual inspection. The differences between sequence patterns indicate that a number of recombination events as well as point mutations occurred in the evolution of $p r t F$ genes. Notably, a mosaic-like structure of the variable region can readily be observed, for instance by comparing the nucleotide sequences for strains M4 (281C), M4 (Umeå), M18 (SS-36), M12 (195/2110) and M12 (100085), where the sequences show a common pattern up to position 59 and then segregate to different variant types. Furthermore, a unique block between nucleotide positions 76 and 111

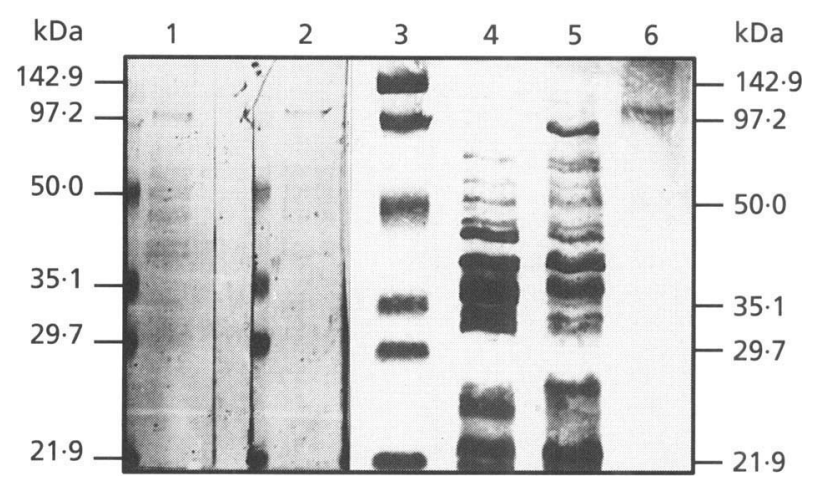

Fig. 4. Purification of recombinant protein F15. Lanes 1 and 2 Western blot examination of purified protein F15 incubated with fibronectin ( $\mathrm{g} \mathrm{I}^{-1}$; lane 1) and fibrinogen $\left(2 \mathrm{~g} \mathrm{I}^{-1}\right.$; lane 2$)$. Lanes 4-6, Coomassie brilliant blue staining of recombinant $E$. coli lysate without induction (lane 4), after induction with IPTG (lane 5) and of purified protein F15 $(20 \mu \mathrm{g}$; lane 6). Lane 3, molecular mass markers. In lanes 1 and 2, minor binding activity was observed in the low-molecular-mass region which represents degradation products of protein F15. The prominent band at approximately $100 \mathrm{kDa}$ in the lysate of the induced culture (lane 5) represents T7 RNA polymerase of the expression host strain (Davanloo et al., 1984).

was present in only three sequences out of 14 ; however, two of them were of sequence type I whereas the third one was of type II (Fig. 3b). The sequence variability was not as high as for $\mathrm{M}$ - or M-like proteins and there was no strict correlation of serotype or $\mathrm{OF}$ expression between different nucleotide sequence patterns. The substitution of DNA sequences observed was most probably due to horizontal genetic transfer, a mechanism also found for other streptococcal virulence genes (Whatmore \& Kehoe, 1994; Kapur et al., 1995).

\section{Characterization of protein F15}

To obtain recombinant protein F15 for purification and biochemical investigation the $p r t F$ gene was amplified and cloned into the pET-21a $(+)$ expression vector through Bam HI and SacI restriction sites introduced to the gene sequence with PCR primers (see primer sequences in Table 1 and Methods). The resulting plasmid, pFNB3, was able to express the protein in $E$. coli strain BL21(DE3) after induction with IPTG (Figs 4 and 5). For E. coli strain BL21(DE3) harbouring plasmid pET-21a(+) without any M-type 15 DNA insert no fibrinogen- or fibronectin-binding activity was observed (Fig. 5).

Protein F15 was purified from a sonicate extract of the recombinant $E$. coli strain carrying $\mathrm{pFNB} 3$. The protein eluted from fibrinogen-Sepharose revealed a single polypeptide band by Coomassie brilliant blue staining after SDS-PAGE and showed reactivity with labelled fibrinogen as well as fibronectin. The protein, when present in crude $E$. coli extract, was stable during longterm storage at $4^{\circ} \mathrm{C}$. Following purification, however, the binding activity for fibrinogen was lost within $48 \mathrm{~h}$, 
(a)

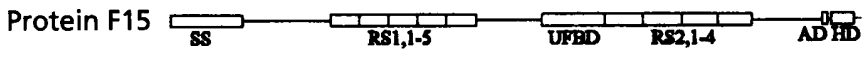

pFNB3

PEFNB31

pEUD15

PEFGR153

pEUFBD15

pEFBR154

(b)
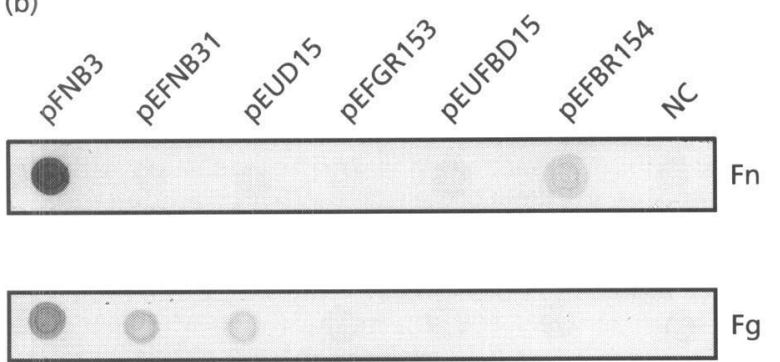

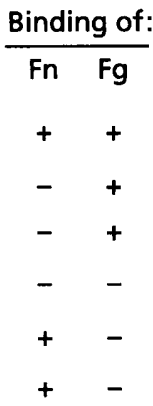

Fig. 5. Localization of the regions of protein F15 interacting with fibronectin and fibrinogen. (a) Representation of recombinant inserts in different plasmids, aligned with the structure of the protein F15 molecule. The following parts of protein $F$ were expressed from the various recombinant plasmids: pFNB3, complete protein F15; pEFNB31, protein F15 truncated from the C-terminus, lacking fibronectinbinding domains; pEUD15, the variable $\mathrm{N}$ terminal domain of protein F15; pEFGR153, five type 1 repeats of unknown function; pEUFBD15, upstream fibronectin-binding domain; pEFBR154, four so-called fibronectin-binding repeats. (b) Interaction of the different protein F15 recombinant fragments with fibronectin (Fn), fibrinogen $(\mathrm{Fg})$ and rabbit antiserum to protein F15 (anti-prtF15). All recombinant polypeptides as in (a); NC, negative control, viz. E. coli BL21(DE3) with pET21a(+) vector. whereas the binding of fibronectin was retained for at least 4 weeks. As tested during purification, the protein was particularly sensitive to a $\mathrm{pH}$ lower than $4 \cdot 0$, perhaps due to protease activation, and the presence of a protease inhibitor was therefore essential to its recovery.

The apparent molecular mass of protein F15 was approximately $100 \mathrm{kDa}$ (Fig. 4), which is higher than that predicted from the deduced amino acid sequence of the recombinant protein. Since it is known that fibrinogen interacts with fibronectin, it was possible that the binding of commercial fibrinogen to protein F15 was in fact due to its content of fibronectin. The preparation was therefore fractionated on collagen-Sepharose to remove any fibronectin. The binding of fibrinogen to protein $\mathrm{F} 15$ was unaffected by this purification step. The purity of the fibrinogen and authenticity of the detection system used were confirmed by Western blot tests with fibronectin- and fibrinogen-specific antibodies (data not shown). The ability of protein F15 to bind other plasma and extracellular matrix proteins was also investigated. Fibrinogen, fibronectin, IgG1, IgG2, IgG3, IgG4, IgA, IgD, IgM, laminin, vitronectin, the complement component $\mathrm{C} 1 \mathrm{q}$, collagen and serum albumin were examined by the dot-blot technique, at an initial load of approximately $4 \mu \mathrm{g}$ of each protein. Protein F15 exhibited binding above background control levels to only fibrinogen and fibronectin (data not shown).

The affinity constants of the interactions of protein F15 with fibronectin and fibrinogen were determined by ELISA. The experiments demonstrated that protein F15 bound fibronectin with higher affinity $\left(K_{\mathrm{a}} 1.8 \times 10^{8}\right.$ $\left.\mathrm{mol}^{-1}\right)$ than it bound fibrinogen $\left(K_{\mathrm{a}} 1.25 \times 10^{7} \mathrm{~mol}^{-1}\right)$.

\section{Mapping of the binding region for fibrinogen}

A truncated variant of protein F15, lacking the Cterminal half, was obtained by expression in E. coli BL21(DE3) of the recombinant plasmid pEFNB31, containing a prtF15 gene fragment generated by PCR using primers 'forward' and 'reverse 2' (see Table 1 and Figs 2 and 5 a). As tested with sonicate extracts of $E$. coli BL21(DE3), containing the respective recombinant plasmids, the protein did not show any detectable binding of fibronectin but still bound fibrinogen. Two recombinant polypeptides expressed from recombinant plasmids pEUFBD15 and pEFBR154, representing the upstream fibronectin-binding domain and fibronectin-binding repeats, bound fibronectin as expected but failed to bind fibrinogen. The polypeptide expressed from plasmid pEFGR153, covering the type 1 sequence repeats, failed to bind either fibrinogen or fibronectin. Recombinant plasmid pEUD15 was generated by AvaI digestion of the plasmid pEFNB31 with subsequent filling to blunt ends and ligation. The polypeptide expressed from this plasmid encompassed the variable $\mathrm{N}$-terminal part of protein $\mathrm{F} 15$ and exhibited binding of fibrinogen but not fibronectin. The rabbit antiserum to protein F15, similarly to fibrinogen, showed preferential binding to the $\mathrm{N}$-terminal part of the protein F15 molecule (Fig. 5).

\section{DISCUSSION}

It is known that the FcRA proteins of some OF-positive 
serotypes of $S$. pyogenes bind fibrinogen in addition to IgG (Stenberg et al., 1992). From the present strain of serotype M15, the gene for the FcRA protein was cloned and sequenced (Katerov et al., 1994). It was found, as expected, that recombinant FcRA15 protein bound fibrinogen and $\operatorname{IgG}$ with high affinity. However, the original streptococcal strain demonstrated high binding of fibrinogen (unpublished data) but only moderate binding of IgG. It was therefore possible that the strain could express more than one fibrinogen-binding protein on its surface. In the present work, a gene larger than the fcrA15 gene, encoding a fibrinogen-binding protein, was identified. Surprisingly, nucleotide sequence comparison of the cloned gene with known genes of $S$. pyogenes revealed extensive sequence similarity and identity with the gene encoding the fibronectin-binding protein $F$. This protein (designated F15), hitherto described as a principal epithelial adhesin, might therefore have additional biological properties of possible importance for the virulence of $S$. pyogenes.

Previously, only the fibronectin-binding region, representing approximately $30 \%$ of the whole molecule, was isolated (Sela et al., 1993). In the present work, the entire recombinant protein F15 was successfully purified by a combination of gel filtration and fibrinogen affinity chromatography. Although stable on the streptococcal surface or in crude extracts of recombinant $E$. coli expressing protein $\mathrm{F} 15$, the protein was increasingly sensitive to degradation during purification. Since the binding of fibronectin was of higher affinity than that of fibrinogen, use of a fibronectin rather than fibrinogen affinity sorbent would seem preferable. On the other hand, the stronger elution conditions required in such case might possibly affect the stability of the protein and therefore cause failure of purification.

Purified protein F15 was tested for interaction with different plasma and extracellular matrix proteins and no binding to proteins other than fibronectin and fibrinogen was found. Also the binding constant for fibrinogen, although lower compared to that for fibronectin, indicated a specific interaction between protein F15 and fibrinogen. The results with recombinant subfragments of protein F15 established that human fibrinogen binds to the N-terminal end of protein F15, which is clearly distinct from the parts of the molecule interacting with fibronectin determined earlier by others and corroborated here (Fig. 5). Our examination using a rabbit antiserum raised to crude preparations of protein $\mathrm{F} 15$ also indicated that the $\mathrm{N}$-terminal end of the protein F15 molecule may be immunodominant. Whether antibodies with such specificity might protect against colonization with $S$. pyogenes is so far unknown.

The biological role of the dual binding affinity of protein F15, shared with certain M-family proteins (Schmidt $e t$ al., 1993) as well as another, unrelated protein of this species (Courtney et al., 1994), remains to be clarified. Binding of fibrinogen was claimed to be essential to the antiphagocytic effect of $M$ protein (Whitnack et al., 1988), and the closely related FcRA proteins, also binding fibrinogen, have been found to account for some antiphagocytic properties (Podbielski et al., 1996). Since protein $\mathrm{F}$ appears to be involved in the binding of streptococci to various epithelial cells, the use of the protein for immune prophylaxis against $S$. pyogenes should be of interest. The information obtained in the present work indicates that, compared to the extensive antigenic variation of streptococcal $M$ protein, the diversity of protein $\mathrm{F}$ may be more limited, which should be advantageous for such potential use.

\section{ACKNOWLEDGEMENTS}

This study was supported by the Royal Swedish Academy of Sciences (Cooperation between Sweden and the former Soviet Union), the Medical Faculty of Lund University, the Crafoord and Alfred Österlund Foundations and the Royal Physiographical Society, Lund.

\section{REFERENCES}

Andersen, J. K. (1984). Electroblotting of multiple gels: a simple apparatus without buffer tank for rapid transfer of proteins from polyacrylamide to nitrocellulose. J Biochem Biophys Methods 10, 203-209.

Ben Nasr, A., Wistedt, A., Ringdahl, Y. \& Sjöbring, U. (1994). Streptokinase activates plasminogen bound to human group C and $\mathrm{G}$ streptococci through M-like proteins. Eur J Biochem 222, 267-276.

Berge, A. \& Sjöbring, U. (1993). PAM, a new plasminogen-binding protein from Streptococcus pyogenes. J Biol Chem 268, 2541725424 .

Chhatwal, G. S., Preissner, K. T., Muller-Berghaus, G. \& Blobel, H. (1987). Specific binding of the human $S$ protein (vitronectin) to streptococci, Staphylococcus aureus, and Escherichia coli. Infect Immun 55, 1878-1883.

Courtney, H. S., Li, Y., Dale, J. B. \& Hasty, D. L. (1994). Cloning, sequencing, and expression of a fibronectin/fibrinogen-binding protein from group A streptococci. Infect Immun 62, 3937-3946.

Davanloo, P., Rosenberg, J. J. D., Dunn, J. J. \& Studier, F. W. (1984). Cloning and expression of the gene for bacteriophage $T 7$ RNA polymerase. Proc Natl Acad Sci USA 81, 2035-2039.

Fischetti, V. A. (1989). Streptococcal M protein : molecular design and biological behavior. Clin Microbiol Rev 2, 285-314.

Friguet, B., Chaffotte, A. F., Djavadi-Ohaniance, L. \& Goldberg, M. E. (1985). Measurement of the true affinity constant in solution of antigen-antibody complexes by enzyme-linked immunosorbent assay. J Immunol Methods 77, 305-319.

Haanes, E. J., Heath, D. G. \& Cleary, P. P. (1992). Architecture of the vir regulons of group A streptococci parallels opacity factor phenotype and M protein class. J Bacteriol 174, 4967-4976.

Hanski, E. \& Caparon, M. (1992). Protein F, a fibronectin-binding protein, is an adhesin of the group A streptococcus Streptococcus pyogenes. Proc Natl Acad Sci USA 89, 6172-6176.

Hanski, E., Horwitz, P. A. \& Caparon, M. G. (1992). Expression of protein F, the fibronectin-binding protein of Streptococcus pyogenes JRS4, in heterologous streptococcal and enterococcal strains promotes their adherence to respiratory epithelial cells. Infect Immun 60, 5119-5125.

Heath, D. G. \& Cleary, P. P. (1989). Fc-receptor and M protein genes of group A streptococci are products of gene duplication. Proc Natl Acad Sci USA 86, 4741-4745. 
Horstmann, R. D., Sievertsen, H. J., Leippe, M. \& Fischetti, V. A. (1992). Role of fibrinogen in complement inhibition by streptococcal M protein. Infect Immun 60, 5036-5041.

Kapur, V., Kanjilal, S., Hamrick, M. R., Li, L.-L., Whittam, T. S., Sewyer, S. A. \& Musser, J. M. (1995). Molecular population genetic analysis of the streptokinase gene of Streptococcus pyogenes: mosaic alleles generated by recombination. Mol Microbiol 16, 509-519.

Katerov, V., Schalén, C. \& Totolian, A. A. (1994). Sequencing of genes within the vir regulon of Streptococcus pyogenes type M15 - an opacity factor-positive serotype with low opacity factor expression. Mol Gen Genet 245, 78-85.

Kostrzynska, M., Schalén, C. \& Wadström, T. (1989). Specific binding of collagen type IV to Streptococcus pyogenes. FEMS Microbiol Lett 59, 229-234.

Kreikemeyer, B., Talay, S. R. \& Chhatwal, G. S. (1995). Characterization of a novel fibronectin-binding surface protein in group A streptococci. Mol Microbiol 17, 137-145.

Kuusela, P., Vartio, T., Vuento, M. \& Myhre, E. B. (1985). Attachment of staphylococci and streptococci on fibronectin, fibronectin fragments, and fibrinogen bound to a solid phase. Infect Immun 50, 77-81.

Laemmli, U. K. (1970). Cleavage of structural proteins during the assembly of the head of bacteriophage T4. Nature 227, 680-685.

Lottenberg, R., Broder, C. C., Boyle, M. D. P., Kain, S. J., Schroeder, B. L. \& Curtiss, R., III (1994). Cloning sequence analysis, and expression in Escherichia coli of a streptococcal plasmin receptor. J Infect Dis 169, 143-149.

Maniatis, T., Fritsch, E. F. \& Sambrook, J. (1982). Molecular Cloning: a Laboratory Manual. Cold Spring Harbor, NY: Cold Spring Harbor Laboratory.

Okada, N., Pentland, A. P., Falk, P. \& Caparon, M. G. (1994). M protein and protein $\mathrm{F}$ act as important determinants of cellspecific tropism of Streptococcus pyogenes in skin tissue. J Clin Invest 94, 965-977.

Perez-Casal, J., Okada, N., Caparon, M. G. \& Scott, J. R. (1995). Role of the conserved C-repeat region of the $M$ protein of Streptococcus pyogenes. Mol Microbiol 15, 907-916.

Podbielski, A., Schnitzler, N., Beyhs, P. \& Boyle, M. D. P. (1996). M-related protein (Mrp) contributes to group A streptococcal resistance to phagocytosis by human granulocytes. Mol Microbiol $19,429-441$.

Rakonjac, J. V., Robbins, J. C. \& Fischetti, V. A. (1995). DNA sequence of the serum opacity factor of group A streptococci: identification of a fibronectin-binding repeat domain. Infect Immun 63, 622-631.

Saiki, R. K., Gelfand, D. H., Stoffel, S., Scharf, S. J., Higuchi, R.,
Horn, G. T., Mullis, K. B. \& Erlich, H. A. (1988). Primer-directed enzymatic amplification of DNA with thermostable DNA polymerase. Science 239, 487-491.

Sanger, F., Nicklen, S. N. \& Coulson, A. R. (1977). DNA sequencing with chain-terminating inhibitors. Proc Natl Acad Sci USA 74, 5463-5467.

Schmidt, K. H., Mann, K., Cooney, J. \& Köhler, W. (1993). Multiple binding of type 3 streptococcal $M$ protein to human fibrinogen, albumin and fibronectin. FEMS Immunol Med Microbiol 7, 135-144.

Sela, S., Aviv, A., Tovi, A., Burstein, l., Caparon, M. G. \& Hanski, E. (1993). Protein F: an adhesin of Streptococcus pyogenes binds fibronectin via two distinct domains. Mol Microbiol 10, 10491055.

Speziale, P., Raucci, G., Meloni, S., Meloni, M. L. \& Wadström, T. (1987). Binding of collagen to group A, B, C, D and G streptococci. FEMS Microbiol Lett 48, 47-51.

Stenberg, L., O'Toole, P. \& Lindahl, G. (1992). Many group A streptococcal strains express two different immunoglobulinbinding proteins, encoded by closely linked genes: characterization of the proteins expressed by four strains of different $M$ type. Mol Microbiol 6, 1185-1194.

Switalski, L. M., Speziale, P., Hook, M., Wadström, T. \& Timpl, R. (1984). Binding of Streptococcus pyogenes to laminin. J Biol Chem 259, 3734-3738.

Talay, S. R., Valentin-Weigand, P., Jerlstrom, P. G., Timmis, K. N. \& Ghhatwal, G. S. (1993). Fibronectin-binding protein of Streptococcus pyogenes: sequence of the binding domain involved in adherence of streptococci to epithelial cells. Infect Immun 60, 3837-3844.

Talay, S. R., Valentin-Weigand, P., Timmis, K. N. \& Chhatwal, G. S. (1994). Domain structure and conserved epitopes of $\mathrm{Sfb}$ protein, the fibronectin-binding adhesin of Streptococcus pyogenes. Mol Microbiol 13, 531-539.

Whatmore, A. M. \& Kehoe, M. (1994). Horizontal gene transfer in the evolution of group A streptococcal emm-like genes: gene mosaics and variation in vir regulons. Mol Microbiol 11, 363-374.

Whitnack, E., Poirier, T. P. \& Beachey, E. H. (1988). Complementmediated opsonization of group A streptococci inhibited by the binding of fibrinogen to surface $\mathrm{M}$ protein fibrillae. In BacteriaHost Cell Interactions, pp. 111-119. Edited by M. A. Horwitz. New York: Alan R. Liss.

Yamada, K. (1982). Isolation of fibronectin from plasma and cells. In Immunochemistry of the Extracellular Matrix, vol. 1, pp. 111-123. Edited by H. Furthmayer. Boca Raton, FL: CRC Press.

Received 26 March 1997; revised 9 September 1997; accepted 25 September 1997. 